\title{
RESEARCH OF OPTIMIZATION MANAGEMENT MODELS IN CONDITIONS OF UNCERTAINTY AND RISKS
}

\section{Debela I. M.}

\section{INTRODUCTION}

Zoning is the basic law of distribution of natural factors on the Earth's surface, the manifestation of which is observed as a sequence of changes in geographical, natural and climatic zones. The climatic zones of Ukraine are characterized by severe negative natural and climatic conditions, which cause high production, household and infrastructure costs, high production costs, and a long payback period. The allocation of zones in the country, regions in which production is characterized by minimal costs requires the development of methodology and deterministic criteria for assessing the quality of alternative management decisions based on the use of mathematical models of socio-economic systems (SES) ${ }^{16}$.

The problems of SES control are fundamentally different from the problems of automatic and automated control of technical systems. This difference is that in technical systems control objectives are exogenous external to the control object, which means the passivity of the control object, the absence of internal (endogenous) goals and as a consequence the ability to determine the optimal algorithm, control law.

The purpose of the high-level system and the endogenous goals of local organizational systems in the general case do not coincide. In this case, the problem of effective management is transformed into the problem of making agreed decisions as a compromise between endogenous and exogenous goals of the system ${ }^{17}$.

Regional SES, as high-level systems, can be presented as complex artificially active, partially formalized systems with endogenous targeting, so the management of such a system should be multifactorial and anti-crisis ${ }^{18}$.

The functioning of socio-economic and production systems in adverse climatic conditions is accompanied by risks of different nature, which is similar to the functioning of systems in times of crisis and uncertainty.

\footnotetext{
${ }^{16}$ Pyatakov E.N. and others, 2020, p. 170-176.

${ }^{17}$ Ibid. P. 177-181.

${ }^{18}$ Debela I.M., 2011/2011, p. 86-91.
} 
Inter-zonal differences in natural and climatic conditions, as uncontrolled factors determine the different efficiency of agricultural production, as part of the socio-economic system of the regional type. In Ukraine, the term "risky agriculture" 19 , is traditionally used, which is firmly established in scientific terminology.

Adverse natural and climatic factors such as infertile soils, soil erosion caused by strong winds and unstable unpredictable weather conditions are the defining characteristics of the zone of risky agriculture. Planning and forecasting of future crops in the zone of risky agriculture is given in conditions of partial uncertainty and requires the adoption of crisis management decisions throughout the process of growing crops.

Considering the process of crop production as a partially determined optimization management system with conditionally predicted dynamics, it is possible to exclude the uncertainty of information about the structure, system parameters due to adverse climatic factors and non-linear dynamics of its existence and development.

The study of formalization methods, construction of mathematical models of control systems in conditions of uncertainty and risk is relevant and open for research.

\section{General statement of the management task in the presence of risks and uncertainties}

In decision support theory, optimization procedures are used to select the "best" of possible alternatives. The quality of the chosen alternative depends on the determinism and completeness of information about the state of the studied system - the object of decision-making.

The process of decision-making modeling can be divided into three classes of problems.

1. Decision-making in terms of complete certainty and determinism of the input parameters of the model.

2. Decision-making in conditions of risk - the input characteristics and parameters of the model are random variables, with a predicted probability distribution function.

3. Decision-making in conditions of uncertainty (full, partial). The input data of the problem are not deterministic, not predictable. It is not possible to assess the impact of factors on management efficiency ${ }^{20}$.

4. Research of models of control systems depending on degree and character of uncertainty of the input information on object of management can be divided into two classes of problems of decision-making: in the conditions

\footnotetext{
${ }^{19}$ Pyatakov E.M. and others, 2020, p. 177-181.

${ }^{20}$ Hamdi \& Taha, 2001/2001, p. 514-517.
} 
of full or partial uncertainty; in the conditions of risk. The input information of decision-making in risk conditions is reflected by the probability distribution function (probability density) of random variables - model parameters. The concept of uncertainty precludes the existence of even such input data.

Depending on the content of the problem, its solution can be deterministic or random values of variables. The determinism of variables determines the only optimal solution in unambiguously defined conditions ${ }^{21}$. Solutions in conditions of stochastic uncertainty can be found by searching for elements of a set of alternatives, each of which with some probability may be the optimal solution. The uncertainty of the solution is due to the significant amount of stochastic and functional relationships, different ways of presenting input data, the impossibility of formalizing some of the studied processes, as a consequence, the inadequacy of the mathematical model.

There are two main types of uncertainty that complicate the process of formalizing the decision-making model:

1) structural, if the criterion of efficiency, the number of partial optimization criteria, their relationship and the degree of influence on the result are not clearly defined;

2) parametric, when some of the parameters of the model are not defined, stochastic, or not deterministic.

In the process of analysis of control systems in conditions of uncertainty there are problems of structural and parametric identification of the model. The decision-making process itself in conditions of uncertainty is divided into two equivalent tasks:

- specification and formalization of the decision-making model;

- choice of methods and algorithms for constructing alternatives taking into account the peculiarities of the chosen decision-making model.

Generalized parametric uncertainty can be represented as a limited range of possible parameter values. The interval can be strictly limited to numerical values given with varying degrees of accuracy, or with vague boundaries descriptive qualitative variables. Given the level of awareness of the decision maker, uncertainty can be formally classified as risk or uncertainty.

Risk assessment is possible if the probabilistic numerical characteristics of the model are known, such as the distribution density function, mathematical expectation, variance of random variables - environmental factors. Numerical characteristics can be deterministic: exact values, or determined according to the law of large numbers, when the sample size is large enough and the value of the parameter loses the property of unpredictability. Or intervals, given with

${ }^{21}$ Hamdi \& Taha, 2001/2001, pp. 25-439. 
a certain confidence probability, if the sample size is not significant (compared to the size of the general population).

Statistical estimation of risk parameters is possible only under the condition of homogeneity of the studied statistical sample. In the conditions of sustainable economic development it is possible. In today's conditions, for most categories of economic risks (economic reorientation, pandemic, dynamic change in supply and demand), this is practically not the case. Therefore, it is advisable to move from risk management to the formalization of uncertainty, i.e., the definition of interval estimates of the studied parameters.

The value distribution function within the interval is determined on the basis of expert estimates as a heuristic probability density function, a fuzzy set membership function, or an interval uncertainty function. This approach necessitates the study of specific methods of economic risk management.

Algorithmization of control systems in the conditions of interval assessments of risks and uncertainties is at the stage of researches and is an actual scientific problem.

The general task of decision-making in the conditions of interval risks and uncertainty includes the following stages ${ }^{22}$ :

1) formation of many possible solution-alternatives

$$
X=\left\{x_{k}\right\},(k=1 \div s)
$$

2) determination of criteria for assessing the quality of alternatives $x \in X$, agreed for the purpose of the study;

3) selection of the optimal solution $\tilde{x} \in X$ from the set of possible alternatives.

The set of possible alternatives $X$ (admissible solutions of the optimization task) is formed on the basis of meaningful analysis and input parameters of the task, possibly in an informal form, as a subset of the domain of the problem constraints in the form of inequalities (1) or equations (2)

$$
\begin{gathered}
G_{j}\left(x, c_{j}\right) \leq 0, \quad j=1 \div m \\
Q_{i}\left(x, c_{i}\right)=0, \quad i=1 \div n
\end{gathered}
$$

where $x-n$ - measurable vector of controlled variables $\left(x \in R^{n}\right)$;

$G_{j}$ - operator-functional that determines the specification of the mathematical model of the corresponding constraint;

${ }^{22}$ Debela I.M., 2011/2011, p. 10-13. 
$c_{i}$ - quantitative estimates of model parameters.

The optimization step involves determining the criteria for selecting alternatives from the set $X$. Assume that each alternative is described by different partial criteria of the expected value of $K_{i}(x)$.

The expected value criterion is actually an extreme value of the utility function. The expected value criterion can be defined as the maximum expected average return, or the minimum expected average costs ${ }^{23}$. That is, on the set $\left\{K_{i}(x)\right\}$ there is a model of quantitative evaluation of the solution $x \in X$ from the set of alternatives.

$$
\tilde{x}=Z(x)=F\left\{b_{i}, K_{i}(x)\right\} \rightarrow \text { exstr }
$$

where $F$ - operator of formalized description of the model structure;

$b_{i}$ - quantitative estimates of model parameters, for example, weights of partial criteria, cost of consumables, product prices.

In the traditional formulation of the optimization task, the extreme value of the utility function is the optimal solution. But a prerequisite is the determinacy of the mathematical model of the object of study, which means complete certainty of the structure and limited quantitative characteristics of the model. In fact, model (1) - (3) does not take into account the degree of uncertainty and incompleteness of information about the structural features of the object of study and stochastic estimation of parameters.

Dynamic optimization systems are characterized by changes in the functioning of the structure, composition and number of parameters, criteria of the expected value over time. That is, for models of such systems it is necessary to formulate a decision-making algorithm for different scenarios of behavior of the external environment $y(t)$-states of nature ${ }^{24}$. Each scenario must correspond to a certain conditionally optimal behavior of the system. Formally, this requirement can be taken into account by including a time factor in model (1) - (3). Then each implementation of a separate scenario of the environment $y(t)$ will correspond to some optimal control $\tilde{x}$ from the set of alternatives $X=\left\{x_{k}\right\},(k=1 \div s)$

$$
\tilde{x}=Z(x, y, t) \rightarrow \text { exstr }, x \in R^{n}, y \in R^{n}
$$

${ }^{23}$ Hamdi \& Taha, 2001/2001, p. 525.

${ }^{24}$ Ibid. P. 526. 


$$
\begin{gathered}
G_{j}\left(x, c_{j}, y, t\right) \leq 0, j=1 \div m ; \\
Q_{i}\left(x, c_{j}, y, t\right)=0, i=1 \div n .
\end{gathered}
$$

The problem of realization of model (4) - (6) consists in unpredictability, uncontrollability of influence of external environment at the level of separate local system ${ }^{25}$. Therefore, only a heuristic approach to estimating the possible values of the function $y(t)$ is possible. For nonstationary systems, constraints (5) - (6), which determine the set of possible alternatives $X$, clearly depend on the chosen environmental behavior scenario and this dependence is not linear.

This means, in particular, that small variations of $y(t)$ can lead to disproportionately large fluctuations in the initial characteristics of the model (financial crisis, inflation, unemployment, etc.). Therefore, for dynamic systems, it is advisable to divide the optimization problem into two separate tasks.

The first task involves the formation of a set of alternatives $X=\left\{x_{-} k\right\}$, $(k=1 \div s) X=\left\{x_{k}\right\},(k=1 \div s)$ and states of nature $y_{i}(t),(i=1 \div n)$ of the studied time interval $\left[t_{0}, t_{n}\right]$ of decision-making. The mathematical model of this task must answer the question "what will happen if we choose a certain state $y_{i}(t) \ldots$... At time $t_{0}$, the goal of the task is considered to be formulated and not variable. This will allow describing mathematically the corresponding objective function, which is optimized by selecting the appropriate values of the controlled variables $x_{k}$. Thus, for each state of nature $y_{i}(t)$ for each moment of time $t_{i}$ the solution $\left\{x_{k}^{i}\right\}$ is determined, which corresponds to the extreme value of the objective function $Z(x, y, t)$.

The second problem is the problem of choosing the strategy of behavior of the studied system at the initial moment $t_{0}$, upon condition that in the interval $\left[t_{0}, t_{n}\right]$ change of the initial solution $x\left(t_{0}\right)$ is not possible.

For example, if the project of management of economic efficiency of new leased sown areas of some agricultural enterprise is considered. This decision is related to the choice of cultivation culture, resource costs, the volume of future deliveries of products, and the market.

Management decision-making is based on analytical assessments of the demand market, the cost of resources, interest rates on credit, the estimated

${ }^{25}$ Petrov E.G. \& Gubenko E.V., 2013, p. 128-135. 
inflation rate, etc. In the process of project implementation, when some decisions are irreversible (purchased seed, paid rent), it is important that at time $t_{0}$ the decision is optimal and economically feasible.

\section{Formalization of the optimization task in conditions of uncertainty and risks}

Mathematically, the uncertainty leads to the introduction into the model (4) - (6) of some random factor $\varepsilon$, which complicates the form of dependence - the function of the description of the studied process $f(x)$

$$
y=f(x, a, \varepsilon)
$$

Assessing the degree of influence of a random factor $\varepsilon$ on the quality of optimization solutions allows adjusting the model, if possible, to eliminate uncertainty.

Weakening the impact of uncertainty can be achieved in several ways. The simplest is to replace random variables $\varepsilon$ with their mathematical expectations $M(\varepsilon)$, i.e. the transition from stochastic to deterministic values:

$$
y=f(x, a, M(\varepsilon)) .
$$

Uncertainty can be eliminated by formalizing the optimization model in the form of:

$$
y=M[f(x, a, \varepsilon)] .
$$

where $M[f(x, a, \varepsilon)]$ - mathematical expectation of the function of description of the studied process.

Then, the generalized optimization task under uncertainty can be represented by a model of the form:

$$
Z(X, \tilde{\varepsilon})=\underset{\substack{\in \\ x \in D}}{\operatorname{exstr}}\left[f_{1}(X), f_{2}(X), \cdots, f_{n}(X) ; \tilde{\varepsilon}\right]
$$

where $\tilde{\varepsilon}-$ vector of random variables, which reflects the uncertainty of the selection procedure of optimization criteria;

$X$ - vector of possible alternative solutions $X=\left\{x_{i}\right\} \in R^{n}$. 
The optimization area $D=D\left(x, \varepsilon_{1}, \varepsilon_{2}\right)$ is limited by the intervals:

$$
\left\{\begin{array}{c}
f_{1}\left(x, a, \varepsilon_{1}\right) \geq b_{i} ; \\
a_{i}\left(x ; \varepsilon_{2}\right) \leq x_{i} \leq b_{i}\left(x ; \varepsilon_{2}\right) \\
x_{i} \geq 0, i=1 \div n
\end{array}\right.
$$

where: $\varepsilon_{1}$ - random variable of a component whose distribution function (or its numerical characteristics) determines the uncertainty of the boundary conditions of the task;

$\varepsilon_{2}$ - deterministic of a component, determines the change in the initial conditions of the task.

Task (10)-(11) belong to the tasks of stochastic programming, the functional dependencies of which are given implicitly.

The construction of such mathematical models involves the replacement of random variables $\varepsilon_{1}, \varepsilon_{2}$ by their mathematical expectations, i.e., the calculation of the integrals of complex functions, which not only increases the error but also significantly complicates the modeling process. An effective way to formalize such tasks is A.M. Tikhonov's ${ }^{26}$ method of regulation reduction of the initial task of stochastic programming to a set of deterministic tasks of mathematical programming with a fixed value of the vector of random variables $\tilde{\varepsilon}$.

Let's consider some predictable strategy of behavior of the studied system. Assume that the previous analysis allows determining the set of alternatives consisting of $n$ possible implementations of a random process - random events $S=\left(S_{1}, S_{2}, \cdots, S_{i, \ldots}, S_{n}\right), i=1 \div n$ each of which can occur separately, or in total $^{27}$.

Combinations of such events will be subsets of the set $S$ and, in fact, the level of the criterion of marginal risk of the selected $m$-variant of the random process:

$$
\begin{gathered}
K^{m}=\left\{S_{1}^{m}, S_{2}^{m}, \cdots, S_{j}^{m}, \cdots, S_{k}^{m}\right\}, \\
S_{j}^{m} \in S, j=1 \div k ; j \leq n .
\end{gathered}
$$

${ }^{26}$ Tikhonov A. N \& Arsenin V. I., 1979/1979, p. 48.

${ }^{27}$ Nakonechny A.N., 1996, p. 42-48. 
Let's denote the set of events with no risk for the selected alternative $A_{j}$ by $M=\left\{M_{i}\right\}$. Then for all possible alternatives with non-zero risk we have a set of criteria: $\tilde{K}=\left\{K_{i}^{j}, M_{i}\right\}$, the estimate of which will be the probabilities $p_{i}\left(K_{i}^{j}\right)$ and $p_{i}\left(M_{i}\right)$, which satisfy the rationing condition

$$
\sum_{j=1}^{k} p_{i}\left(K_{i}^{j}\right)+p_{i}\left(M_{i}\right)=1 .
$$

For each combination of criteria $K_{i}^{j}$ we will correspond to the cost estimate of alternatives $B_{i}^{j}$, then the losses from the implementation of the risky alternative will be

$$
R_{i}=\sum_{j=1}^{k} B_{i}^{j} \cdot p_{i}\left(K_{i}^{j}\right)
$$

If the probabilities of risk events are equal to each other $p_{i}\left(K_{i}^{j}\right)=p_{i}$, then formula (14) will look like:

$$
R_{i}=p_{i} \sum_{j=1}^{k} B_{i}^{j}
$$

Similarly, if the costs estimate of risk-free events $M=\left\{M_{i}\right\}$ is known and equal to $V_{i}=v_{i} \cdot p_{i}\left(M_{i}\right)$, then the total result of the strategy - the predicted state of the system can be calculated as:

$$
V_{i}-R_{i}=Z_{i}
$$

Then:

$$
\tilde{Z}=\max _{\tilde{K}} Z_{i}=\max _{\tilde{K}}\left(V_{i}-R_{i}\right)
$$

- will be the optimal choice for the predicted system behavior strategy. 
Risk in control tasks, as a factor of randomness can be quantified by such numerical characteristics as mathematical expectation, variance, coefficient of variation, variational scope, and more.

The absolute value of risk can be measured by the amount of projected losses from the implementation of the chosen management strategy. For example, as the total level of losses from the implementation of the strategy with risk parameters:

$$
D=\sum_{i=1}^{n} D_{i}=\sum_{i=1}^{n} x_{i} \alpha_{i}
$$

where: $D_{i}$ - quantitative risk assessment by parameter $x_{i}$;

$x_{i}$ - statistical evaluation of the parameter in the absence of risk;

$\alpha_{i}$ - calculated value of risk (probabilistic characteristic).

The relative level of risk on the parameters $x_{i}$ can be defined as a ratio

$$
\rho_{i}=\frac{D_{i}}{x_{i}} \cdot 100 \%
$$

The analytical model of risk management should provide solutions to the following issues:

- definition of the list of the main risk factors and processes;

- risk assessment: risk ratio, probability of risky event;

- acceptable, critical level of losses from the implementation of a risky alternative, other.

Considering individual implementations of risk strategies as a set of random variables, the formalized task of risk management can be written as a random process of obtaining the projected benefit - the level of profitability ${ }^{28}$

$$
U(t, x)=U+\alpha(t, x)-\beta(t, x),
$$

where: $\alpha(t, x) ; \beta(t, x)$ - random processes, the implementation of which for time $t>0$ and selected parameters of the control system is known or predicted;

$\alpha(t)$ - planned income, receipts, payments;

$\beta(t)$ - projected costs, payments;

${ }^{28}$ Vitlinsky V.V. \& Verchenko P.G., 2000/2000, p. 13. 


$$
\alpha(t=0)=0 ; \beta(t=0)=0 ;
$$

$U>0$ - the initial state of the system, which is actually the "start-up capital" at time $t=0$;

$x$-parameter of the model: $x \in R^{n}\left\{-\infty<a_{i} \leq x_{i} \leq b_{i}<+\infty\right\}, i=1 \div n$.

It is assumed that the implementation of a random process (20) is only two random events that form a complete group: 1 - income exceeds costs, 2 -costs exceed income.

Then, the positive dynamics of the process $U(t, x)$ will need a condition:

$$
\frac{M\left(\alpha\left(t_{i}, x\right)\right)}{M\left(\beta\left(t_{i}, x\right)\right)} \geq 1,
$$

where, $M\left(\alpha\left(t_{i}, x\right)\right), M\left(\beta\left(t_{i}, x\right)\right.$ - mathematical expectations of realizations of random processes at a time $t_{i}$.

Condition (21) can be taken into account by introducing an additional restriction: the probability of monotonic growth $U(t, x)$ - increase in capital (profitability) of the enterprise $p(U(t, x))$ should be close to one:

$$
(1-p(U(t, x)) \leq \varepsilon
$$

where, $\varepsilon>0$, rather small value.

The criterion of optimality for risk management tasks will be the maximum of capital at the end of the modeling period $\mathrm{T}$.

Thus, the risk management task is the task of optimizing the function:

$$
\max _{X \in R^{n}} M(X)=\max _{x \in R^{n}} M[\alpha(t, x)-\beta(t, x)],
$$

where $M(X)$ - mathematical expectation of a random variable $[\alpha(t, x)-\beta(t, x)]$.

If the solution of the optimization task (20) - (23) is denoted by $X^{*}$, then the value of risk $R\left(t, X^{*}\right)=1-p(U(t, x))$ is acceptable, as it provides positive dynamics of the process and guarantees financial stability of the object of management. 
Let's specify formula (18) for a separate implementation of the process $U(t, x)$ :

$$
K(t)=K_{0}+A(t)-B(t)
$$

where: $K(t)$ - the amount of capital at the estimated time $t$;

$K_{0}$ - initial capital;

$A(t)$ - income, receipts, profits;

$B(t)$ - deductions, payments, expenses.

Numerical risk assessment can be calculated as the product of the values of the random variable $X(t)$ - management implementations at time $t$ on the vector of interval risk assessments $R$

$$
d=R \cdot(t)=A(t)-B(t),
$$

where $R \in\left(0 ; R_{\max }\right) ; R_{\max }$ - the upper limit of acceptable risk.

Then, the formula (24) is written in the form:

$$
K(t)=K_{0}+R \cdot X(t)
$$

The probability distribution function of a random variable $F(\mathrm{X}(\mathrm{t}))$ is taken as known in advance.

The optimal level of profitability is determined by the stochastic objective function

$$
Z=\max \left(K_{0}+R \cdot X\right)
$$

We assume that at the moment $t=0$ the admissible level of risk is defined, and at $t=1$ the level of risk is not defined value.

Assuming that the distribution function of the values of $X(t)$ is homogeneous, continuous and differentiated on the interval $[0, t]$, the task of choosing the optimal level of risk is to determine the mathematical expectation of a random variable - the level of profitability $Z$, on the time interval

$$
Z=\max _{\widetilde{K}} Z_{i}=\max _{R \in\left(0 ; R_{\max }\right)} Z\left(R, K_{0}\right)=M[Z]=\int_{0}^{t} \mathrm{X}(\mathrm{t}) f(X(t)) d t
$$

where $f(X)$ - differential distribution function of a random variable $X(t)$. 
The degree of variation of risks, within the studied time interval, can be defined as the standard deviation

$$
\sigma=\sqrt{\sigma^{2}}=\left(\int_{0}^{t}[\mathrm{X}(\mathrm{t})-M(X)]^{2} f(\mathrm{X}(\mathrm{t})) d t\right)^{1 / 2} .
$$

The standard deviation is an auxiliary characteristic for determining the limit values - critical levels of risk.

The choice of the optimal level of risk is determined by the behavior of function (28) and the given constraints of the task.

The calculation of the optimal level of risk is complicated if the condition of continuity of the distribution function $\mathrm{X}(\mathrm{t})$ on the study interval $[0, t]$ is not fulfilled, i. e. there are $k$ breakpoints $\left[x_{1}\left(t=t_{k=1}\right), x_{2}\left(t=t_{k}+\Delta t\right), \ldots\right]$.

Dividing the study interval into partial intervals, the boundaries of which are breakpoints, eliminates this complexity. The risk value $R_{k}$ is estimated at each partial interval.

The expected risk is defined as the arithmetic mean of the calculated interval values: $\bar{R}=\frac{\sum_{k} R_{k}}{k}$.

\section{The task of choosing the optimal risk-based management}

Management is the task of minimizing the negative consequences of uncertainty and risks when choosing the strategy and directions of development of the studied system - the object of management. The success and quality of the solution of this task is determined by the stage of formation of the input data of the model: the completeness of statistical information, the predictability of risk factors for the study period, the availability of methods to eliminate uncertainty ${ }^{29}$.

If statistical observations of the studied object or management process are incomplete, insufficiently formalized, or impossible at all, then the uncertainty of the decision to predict the directions of their possible development is clear $^{30}$. Complex computational procedures, cumbersome stochastic models are not always appropriate to implement in practice. Therefore, a step-by-step management decision-making process is used:

- first step - selection of optimal management strategies;

- second step - choice of decision algorithm.

\footnotetext{
${ }^{29}$ Petrov E.G. \& Gubenko E.V., 2013, p. 128-135.

${ }^{30}$ Chumachenko, 2010, p. 18-21.
} 
The decision maker (DM) independently models the management process, determines the structure, parameters of the task and forms a list of steps to implement the chosen strategy. The determining factor in ensuring the quality of management is the practical experience of DM, its fundamental and professional training.

A formalized decision-making algorithm in terms of risk will begin with the definition of the object under study as a complex system. Let the object under study be a complex system consisting of $n$ subsystems $\left(n=\left\{n_{i}\right\}, i=1 \div N\right)$, which form an ordered set of possible states $S=\left\{S_{j}\right\}$, $(j=1 \div m)$.

Let's group the subsets $S=\left\{S_{j}\right\}$ into four groups according to the level of risk:

1) a set of subsets with no risk $S_{1} \in\left\{S_{j}\right\}$;

2) a set of subsets with an acceptable level of risk $S_{2} \in\left\{S_{j}\right\}$;

3) a set of subsets with a critical level of risk $S_{3} \in\left\{S_{j}\right\}$;

4) a set of subsets with a catastrophic level of risk $S_{4} \in\left\{S_{j}\right\}$.

The states of the system $S_{3}$ are the object of control, the purpose of which is to compensate for the risk effects of the environment - the transition from group 3 to group 2, or 1 . The states of the system of subset 4 are considered non-compensatory.

Let's consider a step-by-step process of optimizing the management of such states of the system, namely:

- selection of the optimal control strategy $\left(\vartheta_{k}(k=1 \div l)\right.$, as a set of interrelated operations $\left(g_{t}(t=1 \div s)\right.$, ordered in time;

- selection of optimal management according to the criteria of strategy evaluation.

The management process begins with choosing the optimal strategy $\vartheta_{k}$ from a set of possible strategies $\left(\vartheta_{k} \in \Omega\right)$. The optimal strategy consists of a set of optimal functions - control steps $\vartheta_{k}=\left[g_{1}, g_{2}, \cdots, g_{t}\right]$, the execution of which in the $j$-th step for the state $S_{j}$ uniquely determines the solution $\tilde{y}_{j}=g_{j}\left(S_{j}\right) ; j=1 \div m$. The content of control steps $g_{j}$ (depends on the process of changing the states $S_{j}$ of the system. 
Each individual state of the system $S_{j}$ of the subset $S_{2}$ or $S_{3}$ can be estimated by the level of losses of system efficiency: existing or future decrease in income, decrease in profitability of production, inflationary fluctuations in the level of prices for raw materials, products, etc.

Each state of the system $S_{j}$ can be matched by the cost vector $R_{j}-$ loss of efficiency of the system

$$
R_{j}=\left(r_{j 1}, r_{j 2}, \cdots r_{j i}, r_{j n}\right),
$$

where: $r_{j i}$ - the estimate of the decrease in the efficiency of the subsystem $n$ in the state $S_{j}$ is given per unit time interval of the study.

To compensate for the loss of system efficiency in the states $S_{3}, S_{2}$ one of the possible implementations $\vartheta_{k} \in \Omega$, from the full set of alternatives possible strategies in the state of the system $S_{j}$.can be used.

Each alternative is associated with the cost of its implementation - the price of the alternative. These costs $C_{j i}(=1 \div m)$ can be considered as a cost estimate of the transition of the system from the state $S_{j}$ to the state $S_{i}$ of the set of subsets $S_{3}, S_{2}$.

The set of possible states of the system, their numerical parameters (probability of state $p_{j}$, the corresponding value of losses $C_{j}$ ) are the initial conditions and are formed on the basis of preliminary analysis and statistical characteristics of the research system.

The task of optimizing the solution taking into account the risk can be formulated as the task of finding the extreme value of a comprehensive criterion for the loss of efficiency of the control system.

For example, the transition of the system from the state $S_{j}$ of the set of critical risk level $S_{3}$ to the state $S_{i}$ of the set of acceptable level $S_{2}$ describes the function of the complex criterion $K=\left\{K_{i}\right\}$ :

$$
Z_{j}=\min _{k} \max _{i} \sum_{K}\left(C_{j i}+\sum_{S_{2}} p_{i} \cdot r_{j i} \cdot\left[a_{k}^{j} \times a_{k}^{i}\right]\right),
$$

where: $a_{k}^{j}, a_{k}^{i}$ - are logical functions that determine the fact of choosing a strategy $\vartheta_{k}$ from a set of alternatives $\Omega$; 


$$
\begin{gathered}
a_{k}^{j}=\left\{\begin{array}{l}
1, \text { if in the state } S_{\mathrm{j}} \subset S_{2} \text { the alternative } \vartheta_{k} \text { is accepted } \\
0, \text { alternative } \vartheta_{k} \text { is not accepted in the state } S_{j} \subset S_{2}
\end{array} ;\right. \\
a_{k}^{i}=\left\{\begin{array}{c}
1, \text { of the choice } \vartheta_{k} \text { transfer the systemin the state } S_{\mathrm{i}} \subset S_{3} \\
0, \text { if the transition of the system to the state } S_{i} \subset S_{3} \text { is not choosen }
\end{array} .\right.
\end{gathered}
$$

Task (31) belongs to the class of multicriteria optimization tasks ${ }^{31}$. The input data of this task is the result of predictive modeling of the behavior of the studied system and the external environment - random variables and processes.

Uncertainty in the parameters of the model, the impossibility of formalizing all factors of influence, uncontrollability of variables, a large number of alternatives for possible implementations of the chosen strategy, all this leads to the conclusion about the feasibility of intuitive - expert management methods ${ }^{32}$.

It is possible to specify only the general procedures for selecting the optimal management based on risk:

- determination of the current state and numerical characteristics of the system and the environment;

- forecast calculations of dynamics trends;

- determination of the time interval of system stability, stability of predicted parameters and external factors;

- choice and formalization of the model;

- assessment of quality, adequacy of the model;

- formation of a base of additional parameters, if necessary, to specify the model as a whole, or individual modeling processes;

- model adjustment taking into account additional parameters;

- formation of many alternatives of management strategy;

- choice of the optimal strategy from a set of alternative criteria (31);

- implementation of the chosen management strategy.

The optimal management strategy, descriptively, is an algorithm for the implementation of stable states of the system, which provides the predicted dynamics, compensates the risks and eliminates structural, parametric uncertainty of the research system and external factors.

\footnotetext{
${ }^{31}$ Debela I.M, 2011/2011, p. 39-42.

${ }^{32}$ Lepa E.V \& Debela I.M, 2007/2007, p. 125-133.
} 


\section{CONCLUSION}

The analysis of formalized models of decision-making problems in conditions of complete or partial uncertainty, in terms of risk allows formulating the following conclusions:

1. Control systems in conditions of uncertainty should solve the problems of structural and parametric identification of the model.

2. The decision-making process in conditions of uncertainty should be divided into stages: specification and formalization of the decision-making model; choice of methods and algorithms for constructing alternatives taking into account the peculiarities of the chosen decision-making model.

3. Parametric uncertainty should be considered within the range of possible parameter values.

4. The function of distribution of values within the interval is defined on the basis of expert estimations, as a heuristic function of distribution of probability.

5. The decision maker classifies uncertainty as risk or parametric uncertainty based on management objectives and personal experience.

6. The transition from risk management to the formalization of uncertainty is carried out by determining the interval estimates of the studied parameters.

7. Tasks of qualitative risk assessment include the identification of risk factors, areas of implementation of projected strategies and risk management stages.

8. Risk, as a random factor, can be estimated by the numerical characteristics of the probability distribution function of risk management strategies, such as mathematical expectation, variance, and rate of variation.

9. The problem of risk-based optimization can be formulated as the problem of finding the extreme value of a comprehensive criterion for the loss of efficiency of the control system.

Mathematical models with risk factors should be used to assess the economic efficiency of the implementation of management tasks of objects of economic activity of various forms of ownership.

Knowledge of the level of forecasted risk, the degree of impact and the financial consequences of the implementation of risky decisions allow avoiding critical uncontrolled situations in strategic planning.

\section{SUMMARY}

Complex artificially active, partially formalized systems with endogenous targeting are investigated. The process of crop production is considered as a partially determined optimization management system with conditionally predicted dynamics. Methods of formalization of system states and algorithm of construction of optimization mathematical models in the conditions of 
uncertainty and risks are offered. Optimization of risk management systems is formulated as a task to minimize the negative consequences of uncertainty and risks of choosing alternative strategies and directions of development of the studied system as an object of management.

\section{REFERENCES}

1. Borchik E.Yu., Debela I.N. \& Borodin S.I. (2017). Nechetkaya model' opredeleniya stepeni vliyaniya vneshnikh faktorov na LPR [Fuzzy model for determining the degree of influence of external factors on enterprise]. Information Technology in Modeling, pp. 104-105.

2. Borchik E.Yu., Debela I.N. \& Zverev V.K. (2018). Vybor relevantnykh alternativ prinyatiya resheniy $\mathrm{v}$ ergaticheskikh sistemakh kriticheskogo primeneniya [Selection of relevant decision-making alternatives in ergatic systems of critical application]. Information Technology in Modeling, pp. 88-89.

3. Vitlinsky V.V. \& Verchenko P.G. (2000). Analiz, modelyuvannya ta upravlinnya ekonomichnym ryzykom. [Analysis, modeling and management of economic risk]. Kyiv : KNEU. (in Ukrainian).

4. Debela I.M. (2011). Ekonomiko-matematychne modelyuvannya [Economic and mathematical modeling]. Kherson : KIEL. (in Ukrainian).

5. Debela I.M., Sokolov A.E. \& Sokolova O.V. (2020). Vplyv pryrodnoho seredovyshcha ta klimatu na funktsionuvannya sotsial'noekonomichnykh system rehionalnoho typu [The impact of the natural environment and climate on the functioning of socio-economic systems of the regional type]. III Ushakov readings "River and sea transport: state, problems, prospects". AUMI, pp. 86-91.

6. Erina A.M. (2001). Statystychne modelyuvannya ta prohnozuvann [Statistical modeling and forecasting]. Kyiv : KNEU. (in Ukrainian).

7. Lepa E.V. \& Debela I.M. (2007). Prohnozuvannya sotsialnoekonomichnykh protsesiv [Forecasting of socio-economic processes]. Kherson : Kherson city printing house. (in Ukrainian).

8. Petrov E.G. \& Gubenko E.V. (2013). Usloviya ustoychivogo funktsionirovaniya sotsial'no-ekonomicheskikh sistem [Conditions for sustainable functioning of socio-economic systems]. System research and information technologies, no1, pp. 128-135.

9. Polishchuk L.I. (1984). Modeli mnogokriterial'noy optimizatsii ekonomicheskikh sistem [Models of multicriteria optimization of economic systems]. Novosibirsk : NSU. (in Russian).

10. Pyatakov E.M., Korolenko O.V., Khodakov V.E., Debela I.M. \& Sokolov A.E. (2020). Osoblyvosti rehionalnykh sotsialno-ekonomichnykh system Ukrayiny [Features of regional socio-economic systems of Ukraine]. MINT 2020. pp. 177-181. 
11. Pyatakov E.N., Korolenko A.V., Khodakov V.E., Debela I.N. \& Sokolov A.E. (2020). Snizhenie proyavleniy prirodno-klimaticheskikh faktorov v regionalnykh sotsialno-ekonomicheskikh sistemakh [Reducing the manifestations of natural and climatic factors in regional socio-economic systems]. MINT (2020). pp. 170-176.

12. Tikhonov A. N. \& Arsenin V. Ya. (1979). Metody resheniya nekorrektnykh zadach [Methods for solving incorrect problems]. Moscow : Science. (in Russian).

13. Khodakov V.E. \& Sokolova N.A. (2016). Natural and climatic factors and the development of socio-economic systems [Natural and climatic factors and the development of socio-economic systems]. Kherson: KSMA. (in Ukrainian).

14. Hamdi A., \& Taha. (2001). Vvedenie $\mathrm{v}$ issledovanie operatsiy [Introduction to the study of operations]. Moscow : Williams. (in Russian).

15. Chumachenko O.I. (2010). Metody vyrishennya zadach nechitkoyi optymizatsiyi u systemakh pidtrymky pryynyattya rishennya [Methods for solving fuzzy optimization tasks in decision support systems]. Adaptive automatic control systems, 2 (17), pp.18-21. DOI: https://doi.org/10.20535/ 1560-8956.17.2010.33568.

\section{Information about the author:} Debela Iryna Mykolaivna,

Candidate of Agricultural Sciences, Associate Professor, Associate Professor at the Department of Management and Information Technologies Kherson State Agrarian and Economic University 23, Stritenska str., Kherson, Ukraine, 73006 orcid.org/0000-0001-7990-4202 